\title{
Specifics of the Russian Accordion Timbre in Duet Performance
}

\author{
Vladislav Berezhnoy \\ Russian State Specialized Arts Academy \\ Moscow, Russia \\ e-mail: kupians@mail.ru
}

\begin{abstract}
The article is dedicated to the role of timbre in modern duet accordion performance and also tone and dynamic specifics of the Russian accordion.
\end{abstract}

Keywords-Russian accordion; multi-timbre accordion; timbre; timbre coordination; register; basic registers; timbre drama

\section{INTRODUCTION}

The timbre-register palette of the accordion is a shade or the sound character of a tone. It is that quality which distinguishes one sound from another. In an accordion duet the sound of one performer may be different from the other and could even be very different if necessary (especially in orchestra music with different symphonic orchestra tones).

An accordion players' orchestra sounds bright when there are different timbres or multi-timbre instruments. Each composition has its own sound palette and shows the author's initial idea in the best way. It is an important quality for a performer to find, to keep and to enrich the tone material with new colors. The orchestra's instruments should be perfectly in tune to form an orchestra scale and to have a dynamic scale from ppp to fff. It is important to stress that all issues considered in this article are vital not only for accordion duets, but also for French and Russian accordion players.

\section{THE IMPORTANCE OF TIMBRE}

An important quality of the Russian accordion is a special penetration of the tone defined by the purity of unison setting of two reeds. In the accordion players' duet a wrong setting of one of the instruments may take place in non-academic genres (musette, tango), but in academic performance both accordions should be toned identically. Let's imagine the lyric song by A. Shalaev "A stripe" arranged for the performers' duet on a wrongly tuned reeds of one or two instruments with a specific sharp sound. We will feel immediate aesthetic misbalance and the sharp tone will distort the musical character especially at traditional performances of the melody by two accordions.

This will be even more obvious if one listens to a performance with accordions all playing in the same high pitch. This sound is characteristic for the French "musette" registers and in the Russian accordion construction "musette" is not used. The vibrant sound of this register is more vivid than unison, it sounds rather like a violin vibrato or a cello (but in a very harsh and simple form). It creates a tender sound which is pleasant for the listener's ear and attracts a lot of accordion lovers. But during lyrical folk music performances and also classic and modern academic compositions a wrong setting gives an impression of misplayed music.

\section{The Methodology OF ACCORdion TIMBrE}

We can play chamber, piano, choir and orchestra music with instruments of Jupiter, Acco, Rus` and Mir types. There are 15 standard registers: tone duplication [from 5 to 7] by reed switches, exact unison timbre (combination of the tones in the broken and the straight deck) ready-elected left keycord.

Tone, dynamic and tissue difference in the sound of the four manuals (right key-cord and three manuals in the left key-cord) can be explained by the resonators' different positions inside the left and the right accordion semi-case and also their different voices sizes. In the multi-timbre duet of the ready-elected accordions a composer or an arranger has a chance to combine different tones and to increase, decrease or to straighten a tone or a group of music tissue.

Anton Rubinstein used to say that a grand piano is one hundred and more instruments. A multi-timbre ready-elected accordion or even more a duet of concert accordions may undoubtedly be called a small symphony orchestra. It is important to stress that up to the 1960s the issues of timbre coordination in a duet or a solo accordion performance was not methodologically covered. However, A. Shalaev and N. Krylov, which were playing multi-timbre instruments, managed to get the sound of multi-timbres. Multi-timbre accordions existed but performers didn't use them in academic music.

It should be said that where in a piano timbre there is a string movement frequency, in an organ timbre there is an air column vibration placed inside the tube case, in a domra timbre or a balalaika there is a string fluctuation increased by the specifics of the deck resonator and the accordion's timbre is defined by a metal plate fluctuation (voice). An accordion's small sound element size defines its special timbre characteristics. If in instruments like the piano, the violin or the organ the sound specifics allow the performer to specify overtones, in accordion overtone specification that is 
noticeable for the ear is impossible. The Improvement of the palette of sound options of modern concert accordions and different color combinations in a duet happens by means of ready timbres construction on the basis of four basis registers in the right semi-case of the accordion: in the right deck there is a brighter and clearer sound and in the left deck the sound is rather opaque and silent.

For reeds, two unisons, one an octave higher and one an octave lower, create fifteen different registers. The base of the color variety of the accordion "Jupiter" consists of four timbres: fagot, clarinet, concertina and piccolo. Combining these four timbres creates eleven more registers: fagot and clarinet, fagot and concertina, accordion with fagot, tutti, organ, organ with clarinet, organ with concertina, accordion, celesta, hobo, accordion with piccolo. All timbres containing fagot are transponder registers [5, p.42].

Left three-manual key-cord also has two timbres:

- Bass key-cords. For an accordion, an instrument created in Russia, an important and meaningful foursound or even a six-sound bass has always been characteristic. M.I. Imhanitsky emphasizes: "Its fullsound foundation appeared and still is a firm basis of all the lining above voices, it is capable to color with warmth all music tissue, to underline the power of breath of all tissue vertical" [4, p.190];

- Chromatic buttons. Chromatic buttons with prepared accords as a special accompanying type in the 1960s were just a way of harmonization. A small scale of prepared accords (Sol of the small and Fa\# of the first) is defined by the dense location of this or that appearance of every accord. It also provides harmonic combinations of the quarta-quinta and the terzo combination. Triple sounds of the buttons are a bit silent in comparison with identical accords of the right and chromatic buttons. The buttons' timbre is velvet in the low register (Mi of contra-octave - Mi of the small), clear and bright in the middle register ( $\mathrm{Re}$ of the small - Fa of the first) bright and singing in the high register (Sol of the first - Fa of the second).

If in an accordion solo performance an additional difficulty is the technique of switching from the ready keycord to the chromatic one, then in the duet there's no such problem. Besides, in an ensemble of chromatic button accordions it is possible to present music tissue components only through the chromatic button and bass key-cords and also through their combination. Different combinations of three left key-cords may considerably enrich the timbre palette of a composition.

Music sound shading is important both for orchestra and ensemble performance. As we see, timbre character in modern concert accordions duets may be widely colored. It is accompanied by the presence of 34 timbres in an ensemble fifteen in the right key-cords and two in the left ones. A mechanism of register switching provides specific characteristics of intonation-timbre coloring. In a duet there are both mono-timbres and their different combinations. An ensemble, unlike a single accordion, possesses wider opportunities in orchestra compositions registering. Timbretissue differentiation can be doubled; that is possible as a result of timbre difference between the sound scale of the right and the left key-cords. This quality, arranged by two accordionists, allows using all tissue registers. Their dynamic specifics should be taken into consideration in order to not break voices' functional hierarchy.

\section{TIMBRE USE IN COMPOSITIONS}

\section{A. General Use}

It is important to remark that notation demands for multitimbre and mono-timbre ensembles are the same (functions opposition with keeping of interior functional unity), that's why an opinion that it is easier to compose or instrument a mono-timbre ensemble is wrong. But the means for these demands in a mono-timbre duet are much lower. Modern concert accordion duets have the option to choose the timbre and the sound while a duet of non-register accordions may choose only the character of the sounding. In a mono-timber the specter of actions for different timbre palette achievements is much lower, but articulation, dynamic and texture decisions are important.

In an accordion duet it is important to consider that the more important the essential difference between the music tissue functions, the higher the dynamic, articulation, timbre of tissue contrast should be. For a moderate opposition tissue functions division or individualization may be enough (depending on the situation). In cases where the maximum opposition is needed it is recommended to use both methods at the same time. For instance, in A. Shalaev`s "Moldavian Dance" arrangement for a mono-timbre duet we can see two melodic lines: the theme and its imitation. Using different sound-extraction methods would not be wise, that's why the author tries the method of melodic lines division by tessiture, which allows us to vividly hear both voices "Fig. 1".

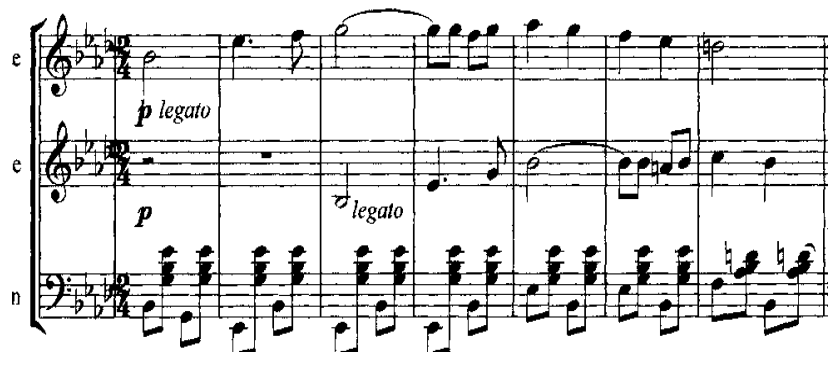

Fig. 1. Moldavian Dance by A. Shalaev.

The combination of similar timbres leads to an increase of their main characteristics. The soft timbre gets softer and the harsh one gets harsher. Mono timbres in accordion player's duets concentrate on accord's quality, the interval, cluster and also decrease dissonance [2, p. 219-220].

\section{B. Tissue Development Principles}

Tissue development principles are an important basis on which many accordion performers work. It is obvious that there can be two kinds of tissue - a mono-plan and multi-plan. 
- Mono-plan timbre.

A mono-plan principle suggests the usage of opaque or bright timbres depending on the character "Fig. 2".

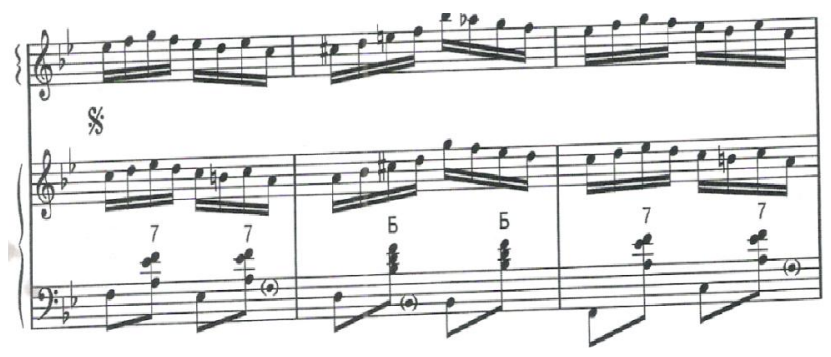

Fig. 2. J. Kukuzenko. Syrba.

Related instruments like domra or balalaika possess individual timbres in a duet. If one is listening to any composition performed on these instruments it is easy to define the domra or the balalaika parts, even if they are played in the same octave. The same may be said about other multi-timbre duets. This principle should be applied to accordionists' ensembles in order to give every instrument its own particular sound coloring. It is important for accordionists' duets to have instruments with rich timbre options. Performers should also possess the necessary skills to incorporate these options.

- Multi-plan timbres.

The combination of contrasting timbres (a bright one and an opaque one) and functional lines creates the second tissue kind - a multi-plan one "Fig. 3".

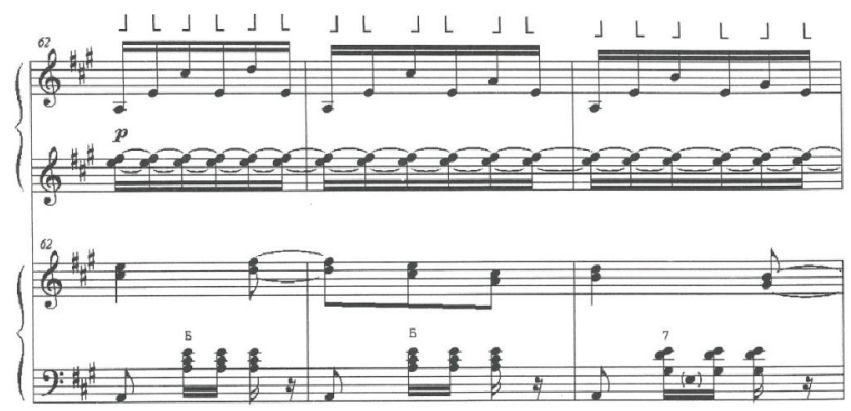

Fig. 3.

It is important to remember that the accordionists can use not only the instruments' timbres, but also their combined timbres. There may be a lot of combination of the ready left and the button key-cords. These multiple combinations allow the performers to hold, if necessary, a melodic, a harmonic, a sub-sound and a bass line at the same time of the same music tissue with different music sounds. Performers perfectly possessing all the multiple sound extraction methods may implement an artistic image in all its timbre variety and use all the shades contained in this timbre.

\section{Using The Full Potential of Timbre}

\section{A. Required playing skills}

Many accordionists who play transcriptions (with no registers) on multi-timbre instruments don't possess enough registration skill. First of all, one should have an idea of the timbre. Multi-timbre accordions with seventeen standard registers (fifteen on the right key-cord and two in the left), four-octave bass and buttons may become an obstacle: by changing the registers mechanically one should be able to differentiate a sound even within a timbre. One just has to remember some outstanding accordionists of the after-war period like N. Rizul and A. Shalae, who played mass produced accordions with ready accords, with no registers and left button keys, and got unique timbre nuances. Even on such instruments the voices of three manuals in different tessitures may remind one of the sounds of a flute, a fagot, a French horn, a tuba and other symphony orchestra instruments. If a performer hears timbre differences on a non-register accordion ("Yasnaya Polyana", "Rubin"), then he will completely incorporate a rich colorful scale on a multi-timbre accordion.

We often experience problems when modern repertoire for an accordion duet (with arrangements or composer's registers) is performed by two-sound instruments. At the same time many accordionists do not follow the register marked by the author.

\section{B. Following the Composition}

Lack of understanding of the transponent role of the required register is also characteristic of professional performers. Yet, one should remember that music tissue transfiguration to a different octave distorts the composer's or the arranger's initial idea. For instance, if a register tutti is marked and there's no remark on another octave, then the voice in the first key will sound an actave lower. Accordingly, when performing the ReMinor Vivaldi-Bach concert on accordion it is necessary to consider register specifics as marked by the author "Fig. 4".

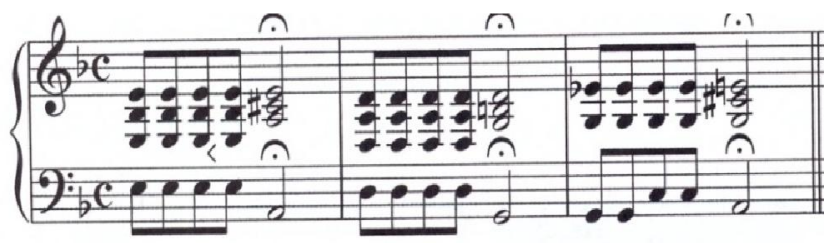

Fig. 4. A.Vivaldi-I. Bach Re Minor Concert.

This example shows that for an ensemble performer performing the second part on a non-register accordion it's important to perform the notation in another octave than it is registered only to transport a more powerful tissue sounding that will be heard in accordance with the author's idea "Fig. $5 "$ ". 


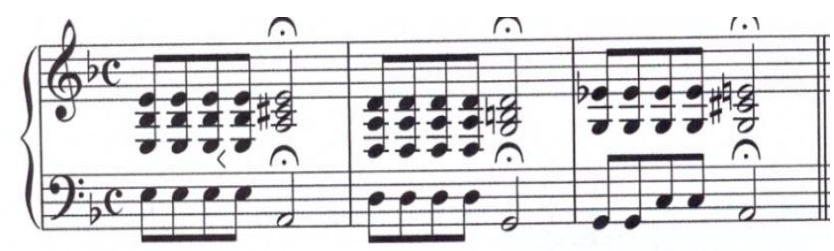

Fig. 5. A.Vivaldi-I.Bach. Re Minor Concert.

Thus, an accordionist or an arranger will be capable of incorporating different colors and shades into the artistic idea only if they can differentiate these timbres.

\section{Artistic Value of Timbre}

It is necessary to stress that a timbre as one of the means of musical language possesses an independent emotional and genre impact. But it completely expresses the power of its impact only in combination with the other musical speech elements. L. Dunaev, for instance, remarks that orchestral means affecting the expressiveness of brass orchestra of N. Ivanov-Radkevich, includes both music tissue components and the timbre ones: "...Imitation of the solo and choir singings acquired by the means of the orchestra: by comparison of the solo, ensemble, tutti and combination of the necessary facture changes" [3, p.76[. The same means may be observed in V1. Zolotarev's accordion duet arrangement "Rondo Cappricioso" and also some other duet transcriptions.

\section{TIMBRE IN CONTEMPORARY ACCORDION MUSIC}

Timbre achievements in music practice in the context of the new timbre spheres are particularly acute for modern duet art. Multiple principles and tendencies of the timbre development of the XXth century separate them from previous centuries. Timbre's importance as emotional, expressive, composition and structure element has risen. Its role has grown in a general architectonics' plot of music compositions. An expression of these processes of composers' art is a difficult and varied expressive side of modern accordion duet compositions. If A. Shalaev's art is based on a folk and dance basis and is characterized by a more common circle of images and music language, then in Vl. Zolotarev's and S. Berinsky's compositions the search for new and unused means of music expression is brightly expressed. The timbre side remains one of the central ones, considering a wide variability in interpretations. Vl. Zolotarev and S. Berinsky try to find new forms for duets.

Modern performers also understand the different folk songs and dances of A.Shalaev. Its innovation is first of all in the composition's register, which was not intended by the author. A good example is "Moldavian Dance" performed by E. Listunova and Ivashkin.

Accordionists and instrumentalists say that the steadiness of the sound and the timbre combination of both parties of the duet depends on what exactly performers, the arranger and the composer are planning to use as expressive means for the theme development as well as new musical material implementation. If performers want to get dynamic growth, it is important to exclude dynamically strong registers, if brightness is important, lighter timbres should be excluded. For any expressive elements it is vital to use the lower tessiture register.

Timbre drama of compositions has individual laws. F.R. Lips writes: "The main role in right registration choice plays the style and the composition content. Generally, the registration plan is kept due to the general architectonics of the composition. It is better to change registers only in some important key moments, on the forms side changes, during the increase or decrease of the number of voices, facture changes, etc." [5, c. 44, 45]. V.V. Vasiliev remarks: "When studying timbre drama for the first time an impression may appear that timbre register switching is equal to the change of orchestra instruments. Yet, it is not like this. Coloring change in the accordion is analogue to the timbre shades of violin and piano, to which the accordion does not give way" [1, c. 79].

In the duet accordion repertoire (in which timbre opportunities double in comparison to solo) transcriptions of orchestra music are predominant. That is why as a rule the first accordion party plays a definite registre (bayan, for instance) and will therefore transfer the color of the sound of the first violins and the button keys in the first octave which will support the cello coloring. At the same time the second ensemble player may change the register if necessary to fit the violin or the piano.

Thus, in modern duet accordion performance we see the increase of importance of the timbre in musical expression. If in 1970 s a timbre was a secondary mean of expression, now it becomes primal.

\section{REFERENCES}

[1] Vasiliev V.V. Russian Composer`s Music of 1970-ies -90-ies and the main tendencies of its performance interprettion. Arts MA theses 17.00.02, Moscow, 2004.

[2] Dunaev L.F. The Science of Instrumentalism Groeth, its development in Russian Music Studies of the Xxth century. 17.00.02. Moscow, 2000 .

[3] Dunaev L.F. Artistic Heritage of N.T. Ivanov-Radkevich - a new stage in instrumentalism developmet for brass orchestra 17.00.02. M., 1977.

[4] Imhanitsky M.I. The History of Accordion art: a Manual. Moscow, Gnesiny Academy. 2006.

[5] Lips F.R. The art of Accordion Perforamce. Moscow, Music, 1998.

[6] Rosenfield N.G., Ivanov M.D. Harmonicas, bayans, accordions: college manual. Moscow, Light Industry, 1974.

[7] Roisman L.I. Organ in the History of Russian Music Culture in 2 volumes. Kazan Conservatory, 2001. Vol.1 